\title{
Polyaniline/ $\mathrm{SiO}_{2}$ 를 이용한 one-pot Mannich 반응: $\beta$-amino carbonyl 화합물의 효율적인 합성
}

\author{
Ajeet A. Yelwande, Balasaheb R. Arbad, and Machhindra K. Lande* \\ Department of Chemistry, Dr. Babasaheb Ambedkar Marathwada University, Aurangabad (M.S.), 431004, India \\ (접수 2010. 12. 12; 수정 2011. 3. 4; 게재확정 2011. 3. 16)
}

\section{Polyaniline/SiO 2 Catalyzed One-pot Mannich Reaction: An Efficient Synthesis of $\beta$-amino Carbonyl Compounds}

\author{
Ajeet A. Yelwande, Balasaheb R. Arbad, and Machhindra K. Lande* \\ Department of Chemistry, Dr. Babasaheb Ambedkar Marathwada University, Aurangabad (M.S.), 431004, India. \\ ${ }^{*}$ E-mail: mkl_chem@yahoo.com
}

(Received December 12, 2010; Revised March 4, 2011; Accepted March 16, 2011)

\begin{abstract}
요 약. Polyaniline/ $\mathrm{SiO}_{2}$ 촉매를 이용하여, acetophenone, aromatic aldehydes와 aromatic amines을 에탄올 용매 속에서 반응 시켜서 다양한 various $\beta$-amino ketones을 one-pot mannich 반응을 수행하였으며, 이 반응을 위해 silica가 충진된 여러 가지 종류의 wt\% polyaniline을 화학적인 산화방법에 의해 합성하였다. 합성한 촉매는 thermal analysis(TG-DTA), X-ray diffraction (XRD), scanning electron microscopy(SEM) energy dispersive spectroscopy(EDS), 및 Fourier transform infrared spectroscopy (FT-IR) 방법으로 확인하였으며, 촉매의 용매에 대한 안정도 UV-Visible spectroscopy로 측정하였다. Polyaniline/ $\mathrm{SiO}_{2}$ 촉매를 이용하는 합성 방법은높은 수율로 얻어지며, work up이 쉽고, 독성이 없으며, 쉽게 회수하여 재사용이 가능하다.
\end{abstract}

주제어: 화학적인 산화반응, Polyaniline/ $\mathrm{SiO}_{2}$, Mannich 반응, $\beta$-amino carbonyl 화합물

\begin{abstract}
Polyaniline $/ \mathrm{SiO}_{2}$ catalyzed one-pot mannich reaction of acetophenone, aromatic aldehydes and aromatic amines are carried out in ethanol to afford various $\beta$-amino ketones. The various $w t \%$ of polyaniline were supported on pure silica synthesized by using chemical oxidative method. The catalyst prepared has been characterized by means of thermal analysis (TG-DTA), X-ray diffraction (XRD), scanning electron microscopy (SEM) energy dispersive spectroscopy (EDS), and Fourier transform infrared spectroscopy (FT-IR). Solvent stability of catalyst was tested using UV-Visible spectroscopy. This protocol has several advantages such as high yield, simple work up procedure, non-toxic, clean, easy recovery and reusability of the catalyst.
\end{abstract}

Keywords: Chemical oxidative method, Polyaniline $/ \mathrm{SiO}_{2}$, Mannich reaction, $\beta$-amino carbonyl compounds

\section{INTRODUCTION}

Polyaniline is an organic conducting polymeric material due to their wide range of electrical, electrochemical, and optical properties as well as their good stability. ${ }^{1-4}$ It is commonly synthesized by oxidizing aniline monomers in bronsted acids using electrochemical or chemical methods.$^{5-7}$ Polyaniline supported catalyst bears good environmental, thermal and chemical stability, electrical and optical properties, facile redox and $\mathrm{pH}$-switching behavior. ${ }^{8}$ Polyanline and polyaniline supported metal oxide has been extensively used as solid acid catalysts for various organic transformations such as oxidation, dehydrogenation, condensation, Michael, Suzuki-Miyaura cross-coupling and esterification reactions. ${ }^{9-16}$
Mannich reaction is one of the most important C-C bond forming reactions in organic synthesis for the preparation of secondary and tertiary amine derivatives. ${ }^{17,18}$ The products of Mannich reaction are mainly $\beta$-amino carbonyl compounds which are important synthetic intermediates for various pharmaceuticals and natural products. ${ }^{19,20}$ Mannich reactions using electrophiles like imines and stable nucleophiles, such as enolates, enol ethers and enamines, have been reported in the literature. ${ }^{21}$ Recently, the reported Mannich reactions have been catalyzed by conc. $\mathrm{HCl}_{1}{ }^{22} \mathrm{NbCl}_{5},{ }^{23} \mathrm{Yb}(\mathrm{OPf})_{3},{ }^{24} \mathrm{PS}^{2} \mathrm{SO}_{3} \mathrm{H},{ }^{25}$ dodecylbenzenesulfonic acid, ${ }^{26} \mathrm{H}_{3} \mathrm{PW}_{12} \mathrm{O}_{40},{ }^{27} \mathrm{HClO}_{4}-\mathrm{SiO}_{2},{ }^{28} \mathrm{SiO}_{2}-$ $\mathrm{OAlCl}_{2}{ }^{29}$ quaternary ammonium salt gemini fluorosurfactants, ${ }^{30}$ ionic liquids, ${ }^{31,32} \mathrm{SnCl}_{2},{ }^{33} \mathrm{BiCl}_{3}{ }^{34}$ and S. Palaniappan et al. reported polyaniline salt ${ }^{35}$ catalyzed Mannich 
reaction with $62-85 \%$ yield of the product. However, some of these methods are plugged by one or other kind of drawbacks such as long reaction time, use of volatile organic solvents, low yields, and harsh reaction conditions. Therefore, it is necessary to develop an improved route for Mannich reaction.

In the continuation of our work, to develop new heterogeneous catalysts for the synthesis of heterocyclic and biologically active compounds, ${ }^{36-38}$ herein, we report a polyaniline $/ \mathrm{SiO}_{2}$ catalyzed three-component Mannich reaction of acetophenone, aromatic aldehydes, and aromatic amines, which led to $\beta$-amino ketones under mild reaction conditions.

\section{EXPERIMENTAL SECTION}

\section{Preparation of pure silica}

Silica samples were synthesized by using sol-gel process. A quantity of $16 \mathrm{~mL}$ tetraethyl ortho-silicate (TEOS) was mixed with $60 \mathrm{~mL}$ of aqueous ammonia. The resulting reaction mixture was stirred continuously for $1 \mathrm{~h}$ at room temperature to obtain uniform silica sphere. The resulting silica material was further retrieved by centrifugation and washed with distilled water and dried at $110^{\circ} \mathrm{C}$ for overnight. Finally, the resulting material was calcined at $500{ }^{\circ} \mathrm{C}$ for $5 \mathrm{~h}$ under air atmosphere to produce solid porous silica materials.

Preparation of polyaniline/ $/ \mathrm{SiO}_{2}$ catalyst. The series of polyaniline $/ \mathrm{SiO}_{2}$ catalytic materials with varying aniline $(10,20,30 \mathrm{wt} \%)$ and $\mathrm{SiO}_{2}$ were prepared by chemical oxidative method. In a typical procedure, $10 \mathrm{wt} \%$ polyaniline $/ \mathrm{SiO}_{2}$ catalysts was synthesized by slowly mixing a solution of $0.3 \mathrm{~mL}$ of aniline in $30.8 \mathrm{~mL}$ of distilled water with $0.61 \mathrm{~mL}$ of concentrated sulphuric acid at $5-10{ }^{\circ} \mathrm{C}$. The resultant mixture was successively slowly treated with $16 \mathrm{~mL}$ of aqueous potassium persulphate (used as an oxidant) and $2.68 \mathrm{~g}$ of solid porous silica. The mixture was kept at $5{ }^{\circ} \mathrm{C}$ and stirring continued for $5-6 \mathrm{~h}$ resulting in a precipitate that was obtained by filtration, washed with distilled water and acetone. The product, polyaniline $/ \mathrm{SiO}_{2}$ salt, was dried in an oven at $70^{\circ} \mathrm{C}$ for $3 \mathrm{~h}$. Similarly 20 and $30 \mathrm{wt} \%$ polyaniline $/ \mathrm{SiO}_{2}$ catalysts were prepared.

\section{Catalyst characterization}

All chemicals were purchased either from Merck or Fluka and used without further purification. Melting points were taken in an open capillary and are uncorrected. TGDTA was performed using PYRIS 1 Thermogravimetric analysis. IR spectra were recorded on JASCO-FT-IR/4100,
Japan, in $\mathrm{KBr}$ disc. Thin layer chromatography was performed on Merck pre-coated silica gel $60-\mathrm{F} 254$ plates. ${ }^{1} \mathrm{H}$ NMR spectra were recorded on an $300 \mathrm{MHz}$ FT-NMR spectrometer in $\mathrm{CDCl}_{3}$ as a solvent and chemical shifts values are recorded $\delta(\mathrm{ppm})$ relative to tetramethylsilane $\left(\mathrm{Me}_{4} \mathrm{Si}\right)$ as an internal standard. The X-ray diffraction (XRD) patterns were recorded on Bruker 8D advance Xray diffractometer using monochromator $\mathrm{Cu}-\mathrm{K} \alpha$ radiation in which wavelength $\lambda=1.5405 \mathrm{~A}^{\circ}$. Scanning electron microscope image with energy dispersive $\mathrm{X}$-ray spectroscopy (SEM-EDS) was obtained on JEOL; JSM-6330 LA operated at $20.0 \mathrm{kV} 1.0000 \mathrm{nA}$.

\section{General Procedure for the Synthesis of $\beta$-Amino Carbonyl Compounds}

A mixture of acetophenone $(5 \mathrm{mmol})$, aromatic aldehydes (5 mmol), aromatic amines $(5 \mathrm{mmol})$ and catalytic amount of polyaniline $/ \mathrm{SiO}_{2}(0.1 \mathrm{~g})$ was refluxed in ethanol $(15 \mathrm{ml})$ for the time mentioned in Table 4 . The progress of the reaction was monitored by thin layer chromatography using pet ether: ethyl acetate as a solvent system. After completion of the reaction, the reaction mass was filtered, the filtrate was concentrated under reduced pressure, and the crude product obtained was recrystallized from ethanol to afford pure products 4(a-i)

\section{Spectroscopic data of compound}

(4a): IR (KBr, cm$\left.{ }^{-1}\right): 3393,3062,1616,1505,1308$, 1414; ${ }^{1} \mathrm{H}$ NMR $\left(300 \mathrm{MHz}, \mathrm{CDCl}_{3}\right.$,): $\delta_{\mathrm{H}}=3.45(\mathrm{dd}, 1 \mathrm{H}$, $J=7.8 \mathrm{~Hz}), 3.54(\mathrm{dd}, 1 \mathrm{H}, J=5.7 \mathrm{~Hz}), 4.51(\mathrm{~s}, 1 \mathrm{H}, \mathrm{NH}), 5.02$ (dd, $1 \mathrm{H}, J=6 \mathrm{~Hz}), 6.54-6.68(2 \mathrm{H}, \mathrm{m}), 7.08-7.15(2 \mathrm{H}, \mathrm{m})$, 7.22-7.34 (4H, m), 7.41-7.53 (3H, m), 7.55-7.58 (2H, m), 7.91-7.94 (2H, m); ES-MS: m/z $302.15\left(\mathrm{~m}^{+}\right)$.

\section{RESULTS AND DISCUSSION}

\section{TG-DTA analysis}

Fig. 1 illustrates the thermal analysis of polyaniline and polyaniline/ $/ \mathrm{SiO}_{2}$. The first weight loss occurs at low temperature $\left(140^{\circ} \mathrm{C}\right)$ for the removal of water molecules from polymer materials. Second weight loss was observed at $200^{\circ} \mathrm{C}$ corresponds to the degradation and decomposition of the polymer back bone. However, complete decomposition occurs at $350^{\circ} \mathrm{C}$ for polyaniline chain shown in Fig. 1(a), (b) shows the thermal decomposition of polyaniline supported on $\mathrm{SiO}_{2}$. From this it can be seen that, the thermal stability of polyaniline/ $/ \mathrm{SiO}_{2}$ materials has noticeably improved, which may be due to the strong interaction between polyaniline and $\mathrm{SiO}_{2}$. The thermal stability is 

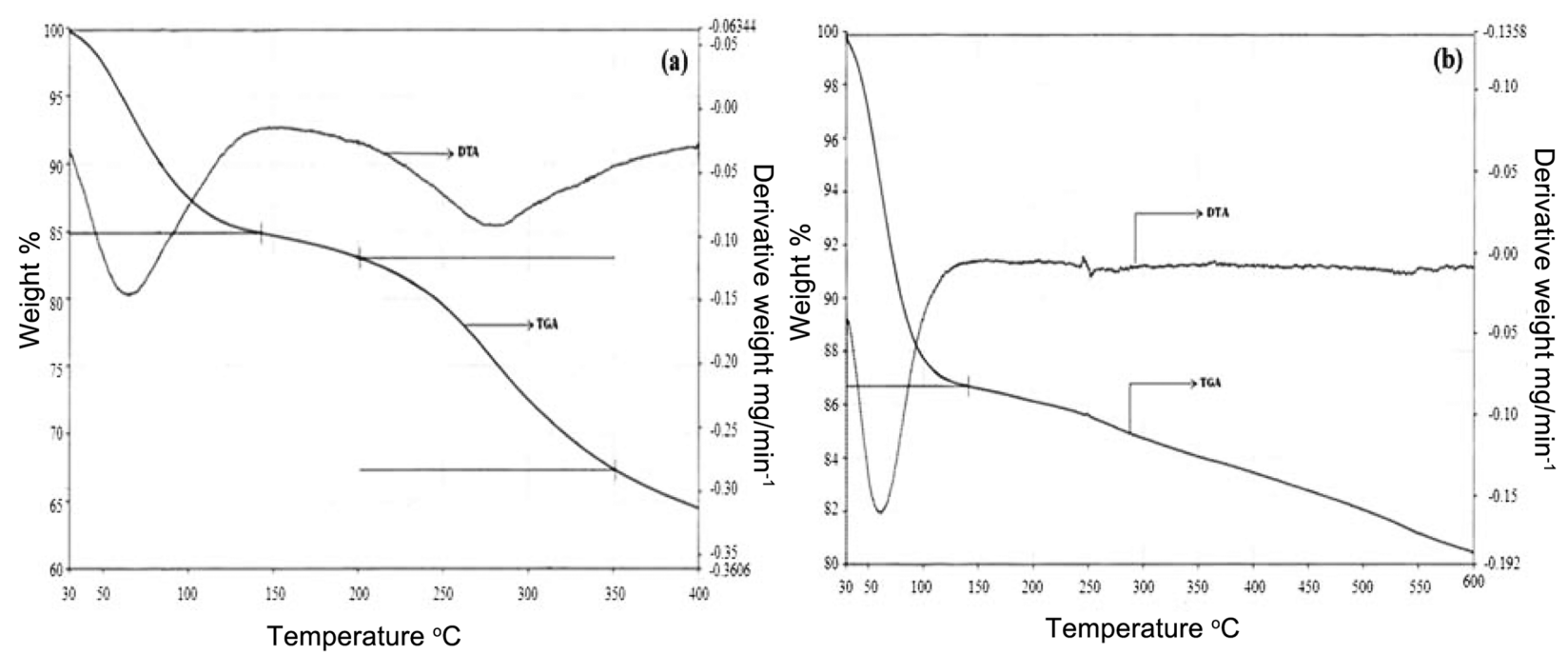

Fig. 1. TG-DTA pattern of (a) polyaniline (b) $10 \mathrm{wt} \%$ polyaniline $/ \mathrm{SiO}_{2}$.

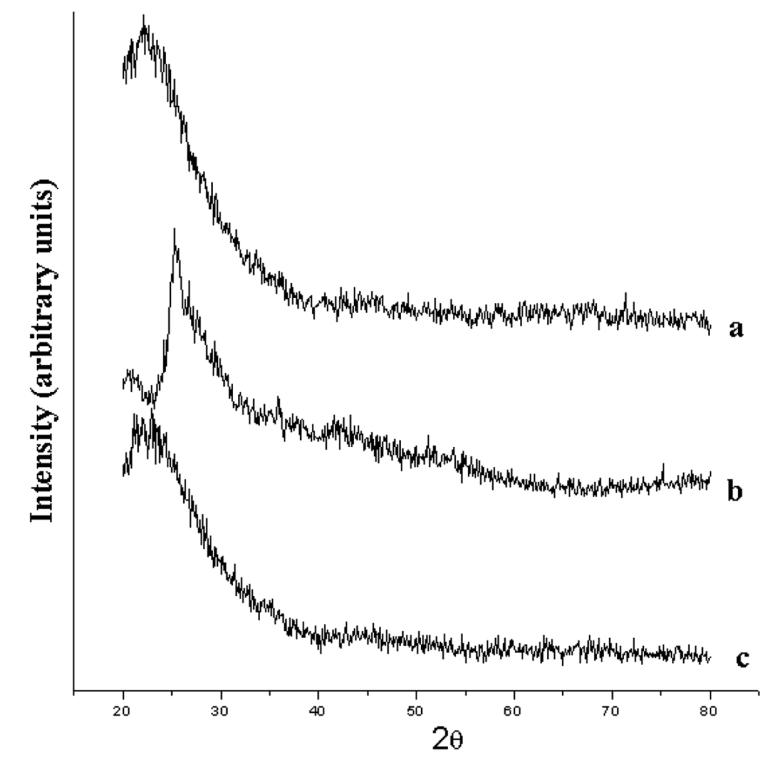

Fig. 2. XRD pattern of (a) $\mathrm{SiO}_{2}$ (b) polyaniline (c) $10 \mathrm{wt} \%$ polyaniline/ $/ \mathrm{SiO}_{2}$.
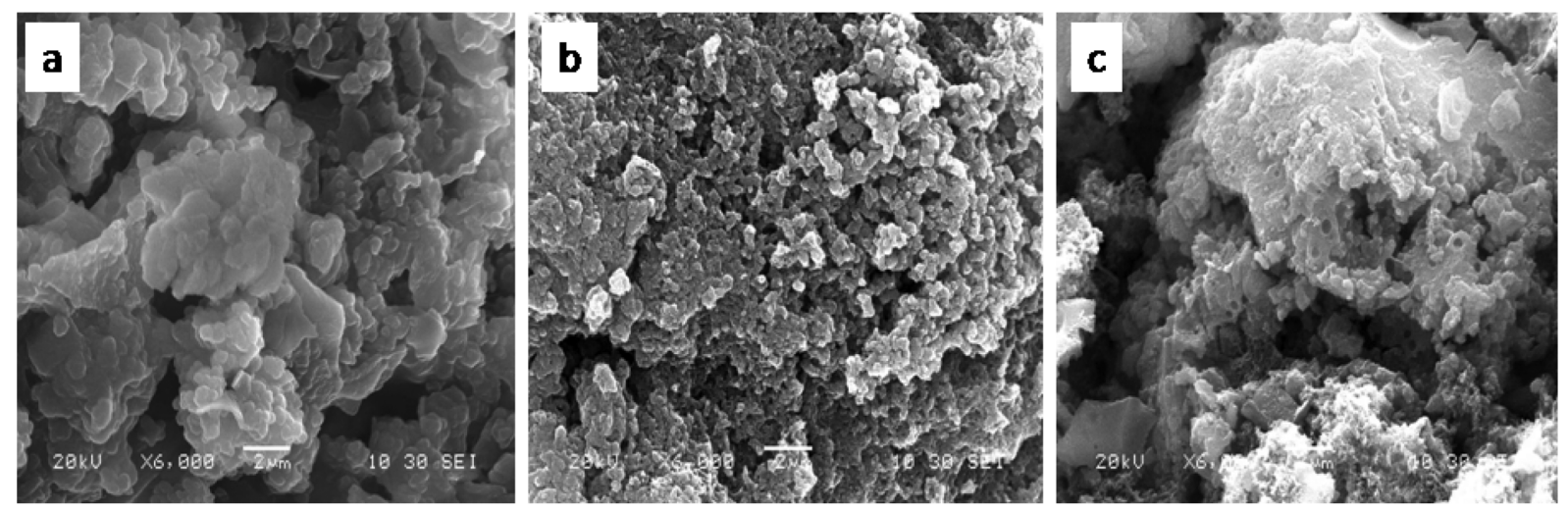

Fig. 3. $\mathrm{SEM}$ image of (a) $\mathrm{SiO}_{2}$ (b) polyaniline (c) $10 \mathrm{wt} \%$ polyaniline $/ \mathrm{SiO}_{2}$. 


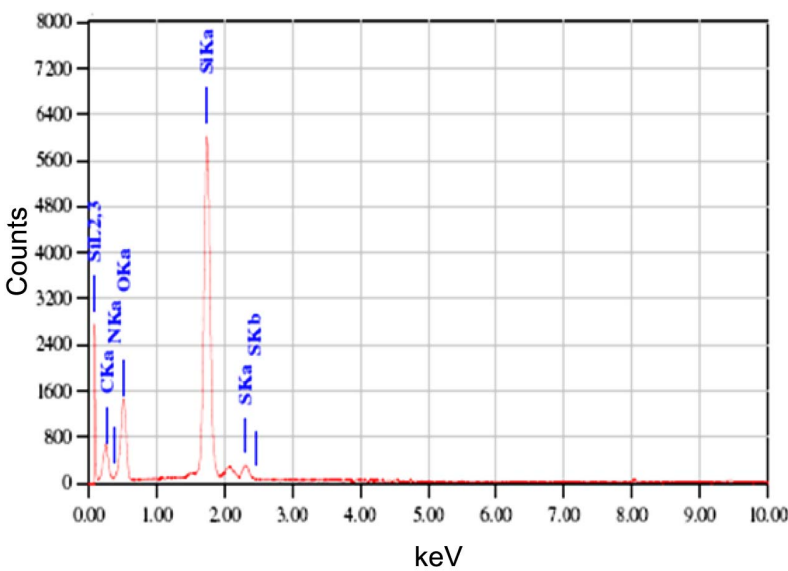

Fig. 4. EDS image of $10 \mathrm{wt} \%$ polyaniline $/ \mathrm{SiO}_{2}$.

or globular morphology was observed in Fig. 3(b) which is the characteristic of polyaniline. ${ }^{41}$ Fig. 3 (c) shows some porosity, it may be due to the insertion of $10 \mathrm{wt} \%$ polyaniline on the surface of $\mathrm{SiO}_{2}$. Finally, from the SEM micrograph, it can be concluded that, the polyaniline addition clearly shows alteration in morphology, which helps to generate the porous materials and the porosity may increases catalytic activity of pure $\mathrm{SiO}_{2}$, as well as polyaniline.

Elemental composition of $10 \mathrm{wt} \%$ polyaniline $/ \mathrm{SiO}_{2}$ catalysts is represented in Fig. 4. The presence of constituent elements $\mathrm{C}, \mathrm{O}, \mathrm{Si}$ and $\mathrm{S}$ as its atomic weight $\%$ are $47.35,39.41,12.51$ and 0.74 respectively. From this analysis it was shown that, the minimum stoichiometric ratio of desired $10 \mathrm{wt} \%$ polyaniline $/ \mathrm{SiO}_{2}$ catalysts was maintained.

\section{FT-IR analysis}

Fig. 5(a-c) shows the FT-IR spectra of the synthesized materials. Fig. 5(a) shows peak at $3477 \mathrm{~cm}^{-1}$ is due to the Si-OH stretching vibration, $1627 \mathrm{~cm}^{-1}$ for the Si-OH bending mode, $1080 \mathrm{~cm}^{-1}$ for Si-O stretching vibration and 815 $\mathrm{cm}^{-1}$ due to the Si-O-Si bending vibration mode. Fig. 5(bc) shows the FT-IR spectra of the pure polyaniline and $10 \mathrm{wt} \%$ polyaniline $/ \mathrm{SiO}_{2}$ respectively. The characteristic peaks of the polyaniline at 3389 and $3371 \mathrm{~cm}^{-1}$ is attributed to $\mathrm{N}-\mathrm{H}$ stretching, 1572 and $1509 \mathrm{~cm}^{-1}$ is due to $\mathrm{C}=\mathrm{C}$ stretching mode of the quinoid ring, 1489 and $1454 \mathrm{~cm}^{-1}$ due to $\mathrm{C}=\mathrm{C}$ stretching vibration of benzenoid ring, 1323 and $1309 \mathrm{~cm}^{-1}$. for $\mathrm{C}-\mathrm{N}$ stretching vibration, $1138 \mathrm{~cm}^{-1}$ for $\mathrm{N}=\mathrm{Q}=\mathrm{N}$, where $\mathrm{Q}$ represents the quinoid ring, peaks at 825 and $808 \mathrm{~cm}^{-1}$ due to aromatic $\mathrm{C}-\mathrm{H}$ bending mode of 1,4-disubstituted benzene ring, Fig. 5(c) shows peak at $1084 \mathrm{~cm}^{-1}$ due the presence of silica.

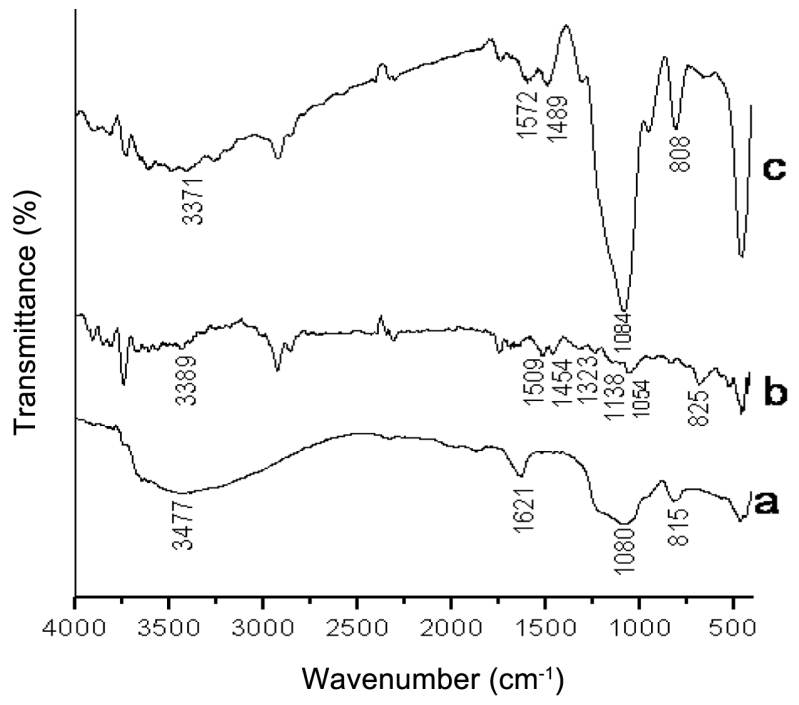

Fig. 5. FT-IR spectra of (a) $\mathrm{SiO}_{2}$ (b) polyaniline (c) $10 \mathrm{wt} \%$ polyaniline $/ \mathrm{SiO}_{2}$.

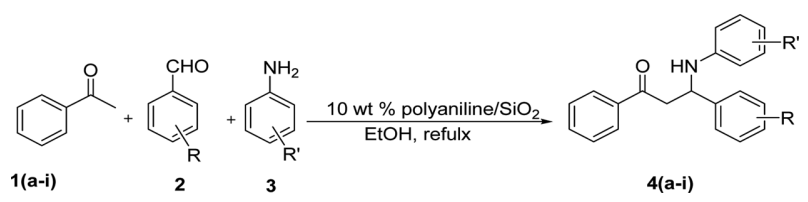

Scheme 1.

\section{Catalytic activity results}

The synthesis of $\beta$-amino carbonyl compounds via condensation of acetophenone, aromatic aldehyde and aromatic amines catalyzed polyaniline/ $\mathrm{SiO}_{2}$, is shown in (Scheme 1).

The stability of the catalyst was tested in different solvents; methanol, acetone, acetonitrile, and ethanol by spectrophotometrically. The results are summarized in Table 1 which shows that the catalyst retains very good stability in ethanol. Hence, in order to get the optimum reaction condition, the reaction of acetophenone, benzaldehyde, and aniline was considered as a standard model reaction.

To examine the effect of the catalyst composition on the activity, various amounts of polyaniline supported $\mathrm{SiO}_{2}$ have been studied and the results are summarized in Table 2. Pure silica shows no catalytic activity (Table 2, entry 2a) and polyaniline exhibits moderate catalytic activity (Table 2, entry 2b) in terms of reaction time and yield of the products. After optimizing the amount of catalyst it was observed that $10 \mathrm{wt} \%$ polyaniline $/ \mathrm{SiO}_{2}$ is sufficient to carry out the reaction smoothly in short time with excellent yields (Table 2 , entry $2 \mathrm{c})$. Increase in $\mathrm{wt} \%(20,30)$ of polyaniline $/ \mathrm{SiO}_{2}$, reaction rate and yield of the product was found to be reduced (Table 2, entry $2 \mathrm{~d}$, e). 
Table 1. Stability of catalyst in various solvent

\begin{tabular}{ccc}
\hline Entry & Solvent & Optical density (O.D.) \\
\hline 1 & Methanol & 0.309 \\
2 & Acetone & 0.264 \\
3 & Acetonitrile & 0.231 \\
4 & Ethanol & 0.179 \\
\hline
\end{tabular}

Table 2. Effect of various amount of polyaniline

\begin{tabular}{cccc}
\hline Entry & Catalyst & Time $(\mathrm{h})$ & Yield $(\%)^{\mathrm{a}}$ \\
\hline $\mathrm{2a}$ & $\mathrm{SiO}_{2}$ & 5 & 0 \\
$2 \mathrm{~b}$ & Polyaniline & 4 & 85 \\
$2 \mathrm{c}$ & $10 \mathrm{wt} \%$ polyaniline $/ \mathrm{SiO}_{2}$ & 3 & 93 \\
$2 \mathrm{~d}$ & $20 \mathrm{wt} \%$ polyaniline $/ \mathrm{SiO}_{2}$ & 4 & 90 \\
$2 \mathrm{e}$ & $30 \mathrm{wt} \%$ polyaniline $/ \mathrm{SiO}_{2}$ & 4 & 87 \\
\hline
\end{tabular}

Reaction conditions: acetophenone $(5 \mathrm{mmol})$, benzaldehyde $(5$ $\mathrm{mmol})$, aniline $(5 \mathrm{mmol})$, catalyst $(0.1 \mathrm{~g})$ and ethanol $15 \mathrm{ml}$. ${ }^{\mathrm{a}}$ Isolated yields

Table 3. Effect of catalyst amount for the mannich reaction of acetophenone, aromatic aldehyde and aromatic amine

\begin{tabular}{cccc}
\hline Entry & Catalyst amount(g) & Time(h) & Yield(\%) \\
\hline 3a & 0 & 4 & - \\
3b & 0.05 & 4 & 81 \\
3c & 0.1 & 3 & 93 \\
3d & 0.15 & 3 & 93 \\
3e & 0.20 & 3 & 93 \\
\hline
\end{tabular}

${ }^{\mathrm{a}}$ Isolated yields.

However, in the absence of catalyst, formation of the desired product was not observed (Table 3, entry 3a). For the investigation of the concentration of catalyst, reaction was carried out under varied amounts of catalyst, such as 0.05 , 0.1, 0.15 and 0.2 gm for standard model reaction (Table 3, entry $3 \mathrm{~b}-\mathrm{e}$ ) and it was observed that $0.1 \mathrm{~g}$ of catalyst is sufficient to complete the reaction efficiently (Table 3 , entry $3 \mathrm{c}$ ).

The scope and generality of the present method was investigated by performing Mannich reactions with various electronically divergent aromatic aldehydes and aromatic amines under optimum reaction conditions (Table 4). Aldehydes bearing different substituents, such as $4-\mathrm{CH}_{3}$, 4- $\mathrm{Cl}$, and $4-\mathrm{NO}_{2}$ were compatible with reactions condition. Aromatic amines bearing 4-Cl, 4- $\mathrm{CH}_{3}$, and 3-Cl were also favorable to those conditions.

Then we turned our attention towards the recovery and reusability of the catalyst as it is important from industrial and economical point of view. The catalyst was separated, washed with n-hexane dried at $80^{\circ} \mathrm{C}$ for $1 \mathrm{~h}$ before the next catalytic run. Reusability of the catalyst was investigated for three times and it was found to retain almost consistent activity (Table 4, entry 4a).
Table 4. $10 \mathrm{wt} \%$ polyaniline/ $\mathrm{SiO}_{2}$ catalyzed mannich reaction of acetophenone, aromatic aldehyde and aromatic amines

\begin{tabular}{cccccc}
\hline Entry & $\mathrm{R}$ & $\mathrm{R}^{\prime}$ & Time $(\mathrm{h})$ & ${\text { Yield }(\%)^{\mathrm{a}}}^{\mathrm{c}}$ & M.p. $\left({ }^{\circ} \mathrm{C}\right)$ \\
\hline 4a. & $\mathrm{H}$ & $\mathrm{H}$ & 3 & $93(93,92,92)^{\mathrm{c}}$ & $170-172$ \\
4b. & $\mathrm{H}$ & $4-\mathrm{Cl}$ & 4 & 92 & $172-173$ \\
4c. & $\mathrm{H}$ & $4-\mathrm{CH}$ & 3 & 91 & $166-168$ \\
4d. & $4-\mathrm{CH}_{3}$ & $\mathrm{H}$ & 4 & 89 & $128-130$ \\
4e. & $4-\mathrm{Cl}$ & $4-\mathrm{Cl}$ & 3 & 88 & $118-120$ \\
4f. & $4-\mathrm{Cl}$ & $4-\mathrm{CH}_{3}$ & 3 & 89 & $115-118$ \\
4g. & $4-\mathrm{NO}_{2}$ & $\mathrm{H}$ & 3 & 90 & $87-89$ \\
4h. & $4-\mathrm{NO}_{2}$ & $3-\mathrm{Cl}$ & 4 & 87 & $99-101$ \\
4i. & $4-\mathrm{NO}_{2}$ & $4-\mathrm{Cl}$ & 3 & 90 & $128-131$ \\
\hline
\end{tabular}

Reaction conditions: acetophenone $(5 \mathrm{mmol})$, benzaldehyde $(5$ $\mathrm{mmol})$, aniline ( $5 \mathrm{mmol})$, catalyst $0.1 \mathrm{gm}$, and ethanol $15 \mathrm{ml}$. ${ }^{\mathrm{a}}$ Isolated yields. ${ }^{c}$ Yield after consecutive cycle

\section{CONCLUSION}

In summary, an efficient catalytic system has been developed for the synthesis of $\beta$-amino ketones using acetophenone, aromatic aldehyde and aromatic amines. Present method offers remarkable advantages such as non-toxic, non-corrosive and an inexpensive reaction conditions. Simple recovery and reusability of the catalyst make the reaction successful under environmental benign conditions.

Acknowledgement. We are grateful to the Head, Department of Chemistry, Dr. Babasaheb Ambedkar Marathwada University, Aurangabad-431004 (MS), India for providing the laboratory facility.

\section{REFERENCES}

1. MacDiarmid, A. G. Synth. Met. 1997, 84, 27.

2. Cao, Y.; Li, S.; Xue, Z.; Guo, D. Synth. Met. 1986, 16, 305.

3. Noufi, R.; Nozik, A. J.; White, J.; Warren, L. F. J. Electrochem. Soc. 1982, 129, 2261.

4. Westerweele, W.; Smith, P.; Heeger, A. J. Adv. Mater. $1995,7,788$.

5. Diaz, A. F.; Logan, J. A. J. Electroanal. Chem. 1980, 111, 111.

6. Watanabe, A.; Mori, K.; Iwabuchi, A.; Iwasaki, Y.; Nakamuraand, Y.; Ito, O. Macromolecules. 1989, 22, 3521.

7. Focke, W. W.; Wnek, G. E.; Wei, Y. J. Phys. Chem. 1987, 91, 5813.

8. Prokes, J.; Stejskal, J. Polym. Degrad. Stab. 2004, 86, 187.

9. Velusamy, S.; Ahmed, M.; Punniyamurthy, T. Org. Lett. 2004, 6, 4821.

10. Devi, C. L.; Olusegun, O. S.; Pavankumar, C. N. S. S.; Rao,V. J.; Palaniappan S. Catal Lett. 2009, 132, 480. 
11. Srinivas, C.; Pavankumar, C. N. S. S.; Rao, V. J.; Palaniappan, S. J. Mol. Catal. A. Chem. 2007, 265, 227.

12. Zhang, A. Q.; Zhang, N.; Hong, S.; Zhang, M. Synth. Commun. 2009, 39, 3024.

13. Palaniappana, S.; Saravananb, C.; Amarnatha, C. A.; Rao, V. J. Catal. Lett. 2004, 97, 1.

14. Patel, A. L.; Talele, H. R.; Rama, H. S.; Bedekar. A. V.; Synth. Commun. 2009, 39, 3016.

15. Kantam, M. L.; Roy, M.; Roy, S.; Sreedhar, B.; Sakunthala, M. S.; Choudaryb, B. M. Lal, R.; Tetrahedron. 2007, 63, 8002.

16. Srinivasan, P.; Malladi, S. R.; Green. Chem. 2002, 4, 53.

17. Arend, M.; Westerman, B.; Angew. Chem. Int. Ed. 1998, 37, 1044

18. Kobayashi, S.; Ishitani, H. Chem. Rev. 1999, 99, 1069.

19. Muller, R.; Goesmann, H.; Waldmann, H. Angew. Chem. Int. Ed. 1999, 38, 184.

20. Suginome, M.; Uehlin, L.; Murakami, M. J. Am. Chem. Soc. 2004, 126, 13196.

21. Matsunaga, S.; Kumagai, N.; Harada, S.; Shibasaki, M. J. Am. Chem. Soc. 2003, 125, 4712.

22. Yi, L.; Lei, H. S.; Zou, J. H.; Xu, X. J. Synthesis 1991, 717.

23. Wang, R.; Li, B. G.; Huang, T. K.; Shi, L.; Lu, X. X. Tetrahedron. Lett. 2007, 48, 2071.

24. Yi, W. B.; Cai, C. J. Fluor. Chem. 2006, 127, 1515.

25. Iimura, S.; Nobutou, D.; Manabe, K.; Kobayashi, S. Chem. Commun. 2003, 1644.

26. Manabe, K.; Kobayashi, S. Org. Lett. 1999, 1, 1965.

27. Azizi, N.; Torkiyan, L.; Saidi, M. R. Org. Lett. 2006, 8, 2079.
28. Bigdeli, M. A.; Nemati, F.; Mahdavinia, G. H. Tetrahedron. Lett. 2007, 48, 6801.

29. Li, Z.; Ma, X. L.; Liu, J.; Feng, X.; Tian, G. Q.; Zhu, A. G. J. Mol. Catal. A. Chem. 2007, 272, 132.

30. Shen, W.; Wang, L. M.; Tian, H.; J. Fluor. Chem. 2008, 129, 267.

31. Li, J. Z.; Peng, Y. Q.; Song, G. H. Catal. Lett. 2005, 102, 159.

32. Fang, D.; Luo, J.; Zhou, X. L.; Liu, Z. L. Catal. Lett. 2007, 116, 76.

33. Wang, M.; Song, Z-G.; Wan, X.; Zhao, S. Monatsh. Chem. 2009, 140, 1205.

34. Li, H.; Zeng, H-Y.; Shao, H-W.; Tetrahydron. Lett. 2009, 50, 6858.

35. Palaniappan, S.; John, A.; Amarnath, C .A. Rao, V. J. J. Mol. Catal. A. Chem. 2004, 218, 47.

36. Katkar, S. S.; Mohite, P. H.; Gadekar, L. S.; Arbad, B. R.; Lande, M. K. Centr Euro. J. Chem. 2010, 8, 320.

37. Katkar, S. S.; Mohite, P. H.; Gadekar, L. S.; Arbad, B. R.; Vidhate, K. N.; Lande, M. K. Chin. Chem. Lett. 2010, 21, 421.

38. Rathod, S.; Arbad, B.; Lande, M. Chin. J. Catal. 2010, 31,631 .

39. Li, Y. Q.; Fu, S. Y.; Yang, Y.; Mai, Y. W. Chem. Mater. 2008, 20, 2637.

40. Raghavendra, S. C.; Khasim, S.; Revanasiddappa, M.; Ambikaprasad, M. V. N. Kulkarrni, A. B. Bull. Mater. Sci. 2003, 26, 733 .

41. Ali, M. A.; Saion, E.; Yahya, N.; Kassim, A.; Dahlan, K. M.; Hashim, S. J. Eng. Sci. Technol. 2007, 2, 111. 